\title{
Replicon typing of F18 fimbriae encoding plasmids of enterotoxigenic and verotoxigenic Escherichia coli strains from porcine postweaning diarrhoea and oedema disease
}

\author{
P.Zs. Fekete ${ }^{\mathrm{a}}$, J. Gerardin ${ }^{\mathrm{b}}$, E. Jacquemin ${ }^{\mathrm{b}}$, J.G. Mainil ${ }^{\mathrm{b}}$, B. Nagy ${ }^{\mathrm{a}, *}$ \\ ${ }^{a}$ Veterinary Medical Research Institute of Hungarian Academy of Sciences, H-1143 Budapest, \\ Hungária krt. 21, P.O. Box 18, Budapest H-1581, Hungary \\ ${ }^{\mathrm{b}}$ Chaire de Bactériologie et de Pathologie des Maladies Bactériennes, Faculté de Médecine Vétérinaire, \\ Université de Liège, Campus du Sart Tilman, Bât B43a, Liège B4000, Belgium
}

Received 3 July 2001; received in revised form 23 November 2001; accepted 27 November 2001

\begin{abstract}
The presence of fimbrial adhesin F18 is frequently found in enterotoxigenic Escherichia coli (ETEC) and verotoxigenic E. coli (VTEC) strains responsible for diarrhoea and oedema disease of weaned pigs. The F18 adhesin occurs in two antigenic variants: F18ab is characteristic of VTEC while F18ac is more typical for ETEC. F18 encoding plasmids of 17 phenotypically characterized porcine E. coli isolates (10 ETEC, 6 VTEC and 1 ETEC/VTEC) were tested with a DNA probe for F18 fimbrial adhesin and with replicon probes for the RepFIa, RepFIb and for the RepFIc family of basic replicons. In all the cases, the F18 probe hybridized to only one plasmid band of size higher than $42 \mathrm{MDa}$. All F18 plasmids were determined to be unireplicon plasmids belonging to the RepFIc replicon family of the $F$ incompatibility complex. There was no difference between F18ac plasmids of ETEC and F18ab plasmids of VTEC strains in terms of replicon type or subtype. However, the size of F18ab plasmids of the VTEC strains varied between 42 and $98 \mathrm{MDa}$, in contrast to F18ac plasmids of ETEC strains (constantly approximately $98 \mathrm{MDa}$ ). (C) 2002 Elsevier Science B.V. All rights reserved.
\end{abstract}

Keywords: Pig-bacteria; Escherichia coli; F18 fimbria; Replicon typing

\section{Introduction}

Although Escherichia coli bacteria belongs to the normal intestinal flora of humans and animals, there are numerous subtypes which can cause severe diarrhoea and other diseases.

\footnotetext{
* Corresponding author. Tel.: +36-1-467-4085; fax: +36-1-467-4076.

E-mail address: bnagy@novell.vmri.hu (B. Nagy). 
Postweaning diarrhoea (PWD) of piglets is frequently caused by the protein toxins of porcine enterotoxigenic E.coli (ETEC) strains. These toxins can be heat labile (LT) which show great similarity with the cholera toxin and/or heat stabile (ST) which are small peptides. In contrast, oedema disease causing strains belong to the verotoxigenic pathotype, and their main virulence factor is a Shiga-like toxin (SLT) variant: the SLT-IIv (Gyles, 1994).

Beside toxic peptide molecules the adhesins are the other main enteric virulence factors of pathogenic E. coli strains. Bertschinger et al. (1990) described the adhesin F107 on the E. coli strain 107/86 isolated from a case of porcine oedema disease. This adhesin was later designated F18ab (Rippinger et al., 1995). The other "enterotoxigenic" variant of the F18 described by Nagy et al. (1992) and Salajka et al. (1992) was structurally similar but antigenically different and later designated as F18ac (Rippinger et al., 1995). F18 fimbriae can be found as characteristic adhesins on ETEC strains causing PWD and on verotoxigenic E. coli (VTEC) strains causing oedema disease in pigs. The F18ab adhesin is typical for VTEC strains and shows relatively low expression in vivo and in vitro, whereas the F18ac is characteristic for ETEC strains (Nagy et al., 1997). The F18 genes were found on plasmids and these genes were often linked with determinants for haemolysin and enterotoxin production (Wittig et al., 1994; Dean-Nyström et al., 1993; Mainil and Remy, unpublished data). Understanding of these plasmids is, however, quite limited.

One way of characterizing bacterial plasmids is to determine their incompatibility group or to determine the type of their origin of replication (Couturier et al., 1988). Such studies were performed on enterotoxigenic E. coli isolates from piglets and cattle (Mainil et al., 1992, 1998), but PWD isolates of porcine ETEC and VTEC producing F18ab or F18ac have not so far been characterized.

The goals of our studies were: (i) to confirm the plasmid localization of the genes encoding for the F18ab and F18ac fimbria expression of porcine ETEC and VTEC; (ii) to identify the replicon types of these F18ab and F18ac plasmids.

\section{Materials and methods}

\subsection{E. coli strains}

The 15 Hungarian E. coli strains tested were isolated from fatal cases of porcine PWD or oedema disease in Hungary, and their phenotype and genotype were described earlier (Nagy et al., 1997) as ETEC (10 strains), as VTEC (four strains) or ETEC/VTEC (one strain). Additional VTEC isolates were included as follows: 107/86 (F107 prototype strain from Switzerland) and $2228\left(\mathrm{~F} 107^{+}\right.$strain from A.D. O'Brien, Bethesda, MD). As negative control, we used the F18 ${ }^{-}$VTEC strain (2206) and the TG1 K12 strain (Table 1).

Furthermore an $s t a^{-}, s t b^{-}$, tetracycline sensitive variant of the ETEC strain E. coli 2173 was produced by removing its enterotoxin and tetracycline resistance plasmid (pTc) while retaining its F18 plasmid (Nagy et al., unpublished data). This strain was designated as NBI 2/11. An $\mathrm{F}_{18}^{+} \mathrm{K} 12$ (XL1Blue $\mathrm{F}^{+} 8^{+}$) E. coli was also produced from the NBI $2 / 11$ derivative of ETEC strain E. coli 2173 by conjugation and included in these studies (designated as 211F18). 
Table 1

ETEC and VTEC strains used in the present study

\begin{tabular}{lllllllll}
\hline Strain & Pathogroup & O group & sta & stb & SLT-IIv & F18ac & F18ab & $h l y$ \\
\hline 2134 & ETEC & O157 & + & + & - & + & - & + \\
2152 & ETEC & O157 & + & + & - & + & - & + \\
2188 & ETEC & O157 & + & + & - & + & - & + \\
2171 & ETEC & O141 & + & + & - & + & - & + \\
2172 & ETEC & O141 & + & + & - & + & - & + \\
2155 & ETEC & O141 & + & + & - & + & - & + \\
2156 & ETEC & O141 & + & + & - & + & - & + \\
2185 & ETEC & O141 & + & + & - & + & - & + \\
2173 & ETEC & O147 & + & + & - & + & - & + \\
2193 & ETEC & OX & + & + & - & + & - & + \\
2203 & ETEC/VTEC & O138 & + & + & + & + & - & + \\
2162 & VTEC & O139 & - & - & + & - & + & + \\
2206 & VTEC & O139 & - & - & - & - & - & + \\
2200 & VTEC & O139 & - & - & + & - & + & + \\
2183 & VTEC & O141 & - & - & + & - & + & + \\
2228 & VTEC & O139 & - & + & + & - & + & + \\
$107 / 86$ & VTEC & O139 & - & - & + & - & + & + \\
NBI 2/11 & ETEC derivative & O147 & - & - & - & + & - & + \\
211 F18 & Transconjugant & - & - & - & - & - & - & - \\
XL1Blue & - & - & - & - & - & - & - & + \\
TG1 & - & & - & - & - & - \\
\hline
\end{tabular}

\subsection{DNA probes and DNA hybridization}

An amplicon obtained from an F107 specific PCR reaction(Imberechts et al., 1994) was used as the F18 specific probe. The replicon probes were DNA fragments derived from the RepFIa, RepFIb, RepFIc basic replicons of plasmids belonging to the F incompatibilty complex and from the RepFIIa and RepI1 subgroups of RepFIc basic replicon (Couturier et al., 1988).

The $\alpha$-haemolysin specific PCR primers (Hess et al., 1986) were used to produce the DNA probe for $h l y$-specific hybridization experiments. Both heat-stable enterotoxin (sta and stb) probes were prepared by specific PCR reactions (Alexa et al., 1997). The DNA probes were labelled and used for hybridization with plasmids within the gels according to Maas et al. (1985).

\subsection{Phenotypic investigation}

Haemolysin production was investigated on blood agar plates containing 5\% defibrinated sheep blood. F18 fimbriae expression was detected on bacteria grown on Isosensitest agar (Oxoid) containing 5\% defibrinated sheep blood, by slide agglutination assays using polyclonal absorbed anti-F18 rabbit serum in 1:20 dilution as described (Nagy et al., 1992).

The antibiotic resistance patterns of the strains used in the F18 conjugation experiments were determined by using test discs containing ampicillin, $10 \mu \mathrm{g}$; chloramphenicol, $30 \mu \mathrm{g}$; kanamycin, $30 \mu \mathrm{g}$; nalidixic acid, $30 \mu \mathrm{g}$; oxytetracycline, $30 \mu \mathrm{g}$; streptomycin, $25 \mu \mathrm{g}$; tetracycline, $30 \mu \mathrm{g}$. 


\subsection{Plasmid DNA isolation}

Plasmid DNA was isolated from the E. coli strains by a modified Kado and Liu (1981) extraction method (Broes et al., 1988). The plasmids were electrophoresed in $0.5 \%$ TAE agarose gels. The gels were dried for prehybridization and for the hybridization with the ${ }^{32} \mathrm{P}$ labelled F18 and the Rep probes. Hybridization was performed directly in the gel as described (Mainil et al., 1992). Undigested plasmid DNA for southern hybridization studies was purified according to the diatomaceous earth method (Carter and Milton, 1993). For the F18 hybridiziation, we used the F18 ${ }^{-}$VTEC strain (2206) and the TG1 K12 strain as negative controls. In all the other ETEC and VTEC strains the F18 gene was detected earlier (Nagy et al., 1997). The control plasmids were the F'lacpro (for FIa), the R1drd19 (for FIb), the P307 (for FIc), the pULB2401 (for FIIa) and the pULB2428 (for the RepI1 type). The four plasmids (98, 42, 23.9 and 4.6 MDa) of the strain 39R681 served as a molecular weight markers.

\subsection{Plasmid transfer by conjugation}

The donor (E. coli NBI 2/11) and the recipient (E. coli K12 XL1Blue) bacteria were grown in $3 \mathrm{ml}$ Luria-Bertani (LB) broth (Maniatis et al., 1989) at $37{ }^{\circ} \mathrm{C}$ overnight. The next day, $100 \mu \mathrm{l}$ of the donor and $100 \mathrm{ml}$ of the recipient bacterial cultures were mixed on LB agar plates, which contained no antibiotics and incubated at $37{ }^{\circ} \mathrm{C}$ overnight. The bacterial lawn of the plate was suspended in $5 \mathrm{ml}$ saline. This suspension was diluted and $100 \mu \mathrm{l}$ were inoculated onto $5 \%$ sheep blood containing agar with $10 \mu \mathrm{g} / \mathrm{ml}$ final concentration of tetracycline added. After overnight incubation at $37{ }^{\circ} \mathrm{C}$, the haemolytic colonies were collected, and after the confirmation of the $\mathrm{Tet}^{\mathrm{R}}, \mathrm{Hly}^{+}$phenotype, one isolate proved to be suitable for further experiments.

\section{Results}

\subsection{Pathotypes and plasmid population of the strains}

From the 17 postweaning E. coli strains five strains expressed F18ab (VTEC strains), and 11 strains expressed F18ac (ETEC and ETEC/VTEC strains) (Table 1). One strain (2206) did not express F18 fimbria and did not contain F18 plasmid. All of the 10 ETEC strains contained two large size (about $100 \mathrm{MDa}$ ) plasmids, but in addition numerous medium and small (approximately 2-10 MDa ) plasmids were also detectable. The VTEC strains contained mainly high molecular weight (>20 MDa) plasmids (Fig. 1).

\subsection{Identification of the F18 adhesin plasmids by probe hybridization}

The F18 adhesin encoding plasmids were detected by hybridization in agarose gels with the labelled PCR product derived from the E. coli 107/86 by F18 specific oligonucleotide primers. In all $\mathrm{F} 18^{+}$phenotype strains, we found the F18 gene, localized on one plasmid of $>42 \mathrm{MDa}$ (Fig. 1). The molecular weights of the F18ac encoding plasmids from the 10 ETEC strains proved to be similar (approximately $98 \mathrm{MDa}$ ). However, the sizes of the 


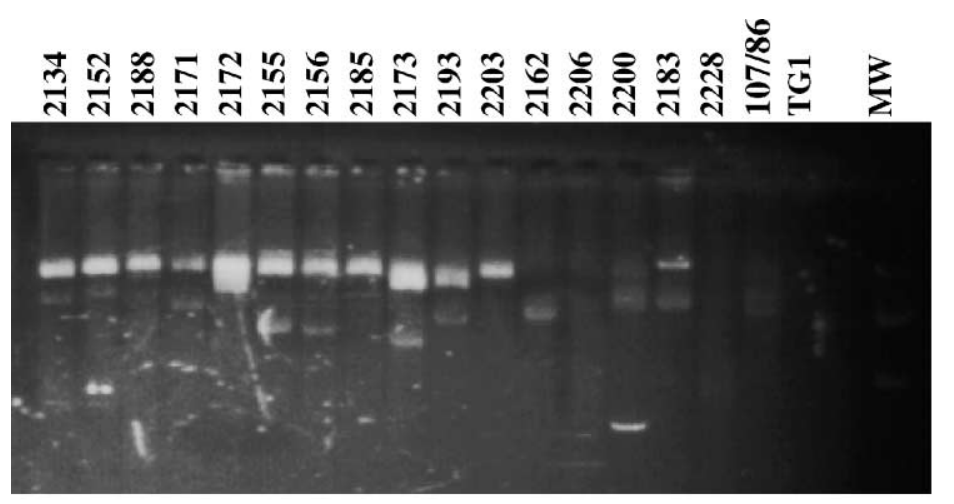

Mda

98

42

23.9

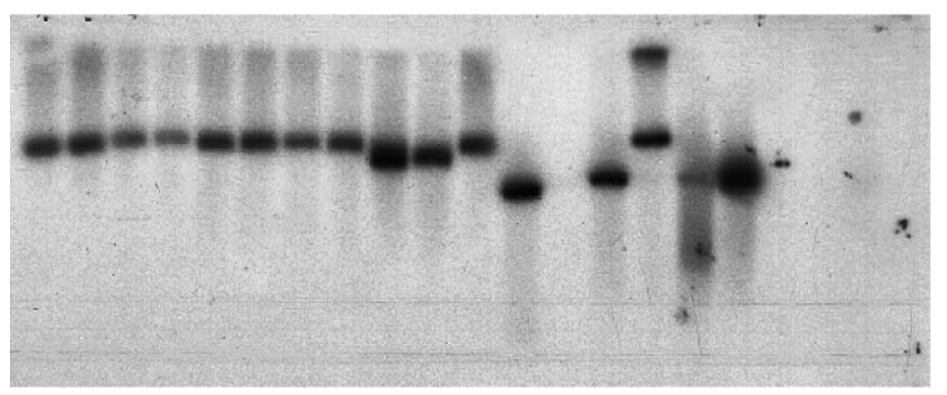

Fig. 1. Ethidium bromide stained TAE agarose $(0.5 \%)$ gel showing undigested plasmids of porcine postweaning ETEC (2134-2193), ETEC/VTEC (2203) and VTEC (2162-107/86) strains and the results of DNA hybridization performed in the gel with ${ }^{32} \mathrm{P}$ labelled $\mathrm{F} 18$ probe, showing specific labelling of one large plasmid of uniform size in ETEC strains and of plasmids of various sizes in VTEC strains.

F18ab plasmid in five VTEC isolates (expressing F18ab) varied (ranged between 42 and $98 \mathrm{MDa}$ ) (Fig. 1).

\subsection{Replicon typing of the F18 plasmids}

No plasmids of the tested strains reacted with the FIa and FIb replicon probes (Table 2). The F18 plasmids hybridized with the probes belonging to the RepFIc family (Figs. 2-4, and Table 2). The subgroup distribution of the FIc type of the 16 plasmids that hybridized with the F18 probes was as follows: FIc (1/16), FIc/FIIa (10/16), FIc/I1 (1/16), FIc/FIIa/I1 (4/16). There was no difference between F18ab and F18ac plasmids of ETEC and/or VTEC strains in terms of replicon type or subtype (subgroup).

3.4. Characterization of the F18ac encoding plasmid of the E. coli 2173 and its K12 transconjugant

A tetracycline-sensitive F18ac-positive, haemolytic donor strain (NB 2/11) was mated with a tetracycline resistant no-haemolytic recipient strain (XL1Blue). The mating mixture was plated on blood agar containing tetracycline and a haemolytic colony (211F18) and 
Table 2

Results of F18 hybridization and replicon typing of the high molecular weight plasmids

\begin{tabular}{|c|c|c|c|c|c|c|c|c|}
\hline Strain & $\begin{array}{l}\text { Number of } \\
\text { plasmids }\end{array}$ & $\begin{array}{l}\text { Position of the } \\
\text { F18 plasmid }\end{array}$ & Rep type & RepFIa & RepFIb & RepFIc & RepFIIa & RepI1 \\
\hline 2134 & 4 & $2^{\mathrm{a}}$ & FIc/FIIa/I1 & - & - & $1,2,3^{\mathrm{a}}$ & $1,2,3^{\mathrm{a}}$ & $1,2^{\mathrm{a}}$ \\
\hline 2152 & 3 & 2 & FIc/FIIa/I1 & - & - & $1,2,3$ & $1,2,3$ & 1,2 \\
\hline 2188 & 3 & 2 & FIc/FIIa & - & - & $1,2,3$ & $1,2,3$ & 1 \\
\hline 2171 & 2 & 1 & FIc/FIIa & - & - & 1 & 1 & - \\
\hline 2172 & 3 & 1 & FIc/FIIa & - & - & 1 & 1 & 1 \\
\hline 2155 & 3 & 2 & FIc/FIIa & - & - & 2 & 2 & - \\
\hline 2156 & 3 & 2 & FIc/FIIa & - & - & 2 & 2 & - \\
\hline 2185 & 2 & 2 & FIc/FIIa/I1 & - & - & 2 & 2 & 2 \\
\hline 2173 & 3 & 1 & FIc/FIIa/I1 & - & - & 1 & 1 & 1,2 \\
\hline 2193 & 3 & 1 & FIc/I1 & - & - & 1 & 1 & 1 \\
\hline 2203 & 2 & 1 & FIc/FIIa & - & - & 1 & 1 & - \\
\hline 2162 & 1 & 1 & FIc/FIIa & - & - & 1 & 1 & - \\
\hline 2206 & 1 & - & - & - & - & - & - & \\
\hline 2200 & 3 & 2 & FIc/FIIa & - & - & 1,2 & 2 & 1 \\
\hline 2183 & 2 & 1 & FIc/FIIa & - & - & 1 & 1 & - \\
\hline 2228 & 1 & 1 & FIc & - & - & 1 & - & - \\
\hline $107 / 86$ & 3 & 3 & FIc/FIIa & - & - & 2,3 & 2,3 & - \\
\hline
\end{tabular}

${ }^{\text {a }}$ Position(s) of the plasmid(s) downwards from the well.
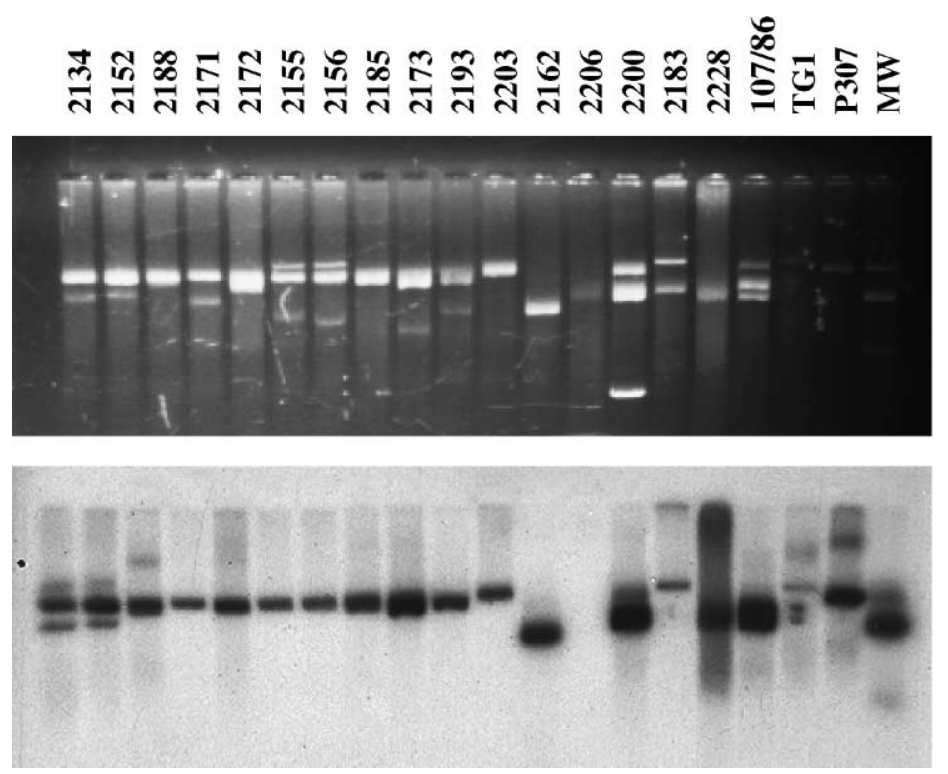

Fig. 2. Same plasmids as in Fig. 1 and their DNA hybridization analysis with replicon probe FIc showing labelling of the plasmids of the tested ETEC and VTEC strains. Clear labelling of the positive control P307 is seen (for FIc). 

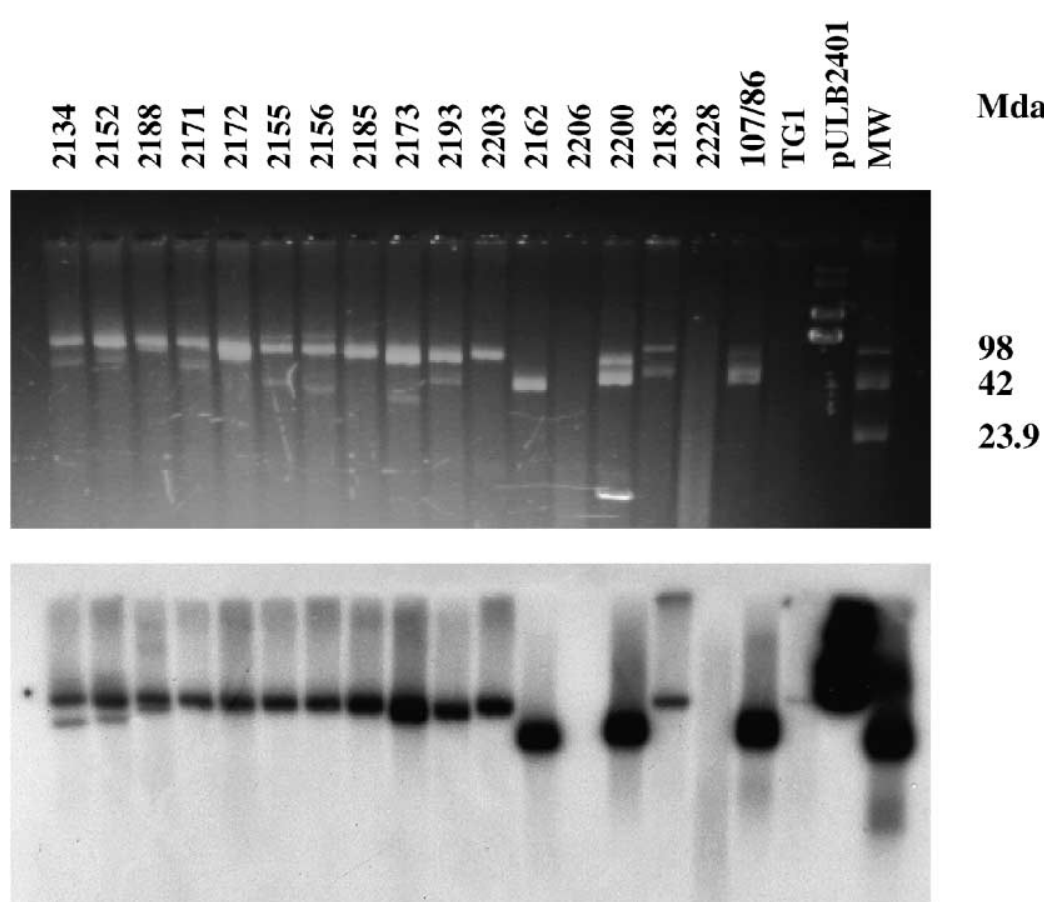

8

23.9

Fig. 3. Same plasmids as in Fig. 1 and their DNA hybridization analysis with replicon probe FIIa (subtype of FIc) showing labelling of the plasmids of the tested ETEC and VTEC strains. Clear labelling of the the positive control pULB2401 is seen (for FIIa).

shown to be a derivative of XL1Blue. $\alpha$-Haemolysin- and F18-specific probes were used to show that the hly gene was localized on the plasmid coding for F18ac. Strain 211F18 expressed F18ac fimbriae.

\section{Discussion}

Numerous genes encoding virulence factors (toxins and fimbriae) in pathogenic E. coli are localized on uni- or multireplicon plasmids which belong to the FIc replicon family of the F incompatibility complex (Mainil et al., 1992, 1998). Most of fimbrial adhesins of ETEC, and some of the F18 fimbriae of porcine VTEC, are produced by genes on plasmids, but so far only a limited information is available about these plasmids. Recently, the replication origins of enterotoxin and fimbrial adhesin encoding plasmids of porcine ETEC were determined (Mainil et al., 1998). These researchers also found that the virulence plasmids mainly belong to the FIc group of the F complex beside FIb (which was also frequent). Interestingly, in our studies the FIc unireplicon type of origin was characteristic of plasmids encoding the adhesins F18ab and F18ac. This in contrast with the findings of Mainil et al. (1998) for ETEC strains from suckling piglets where about half of the 

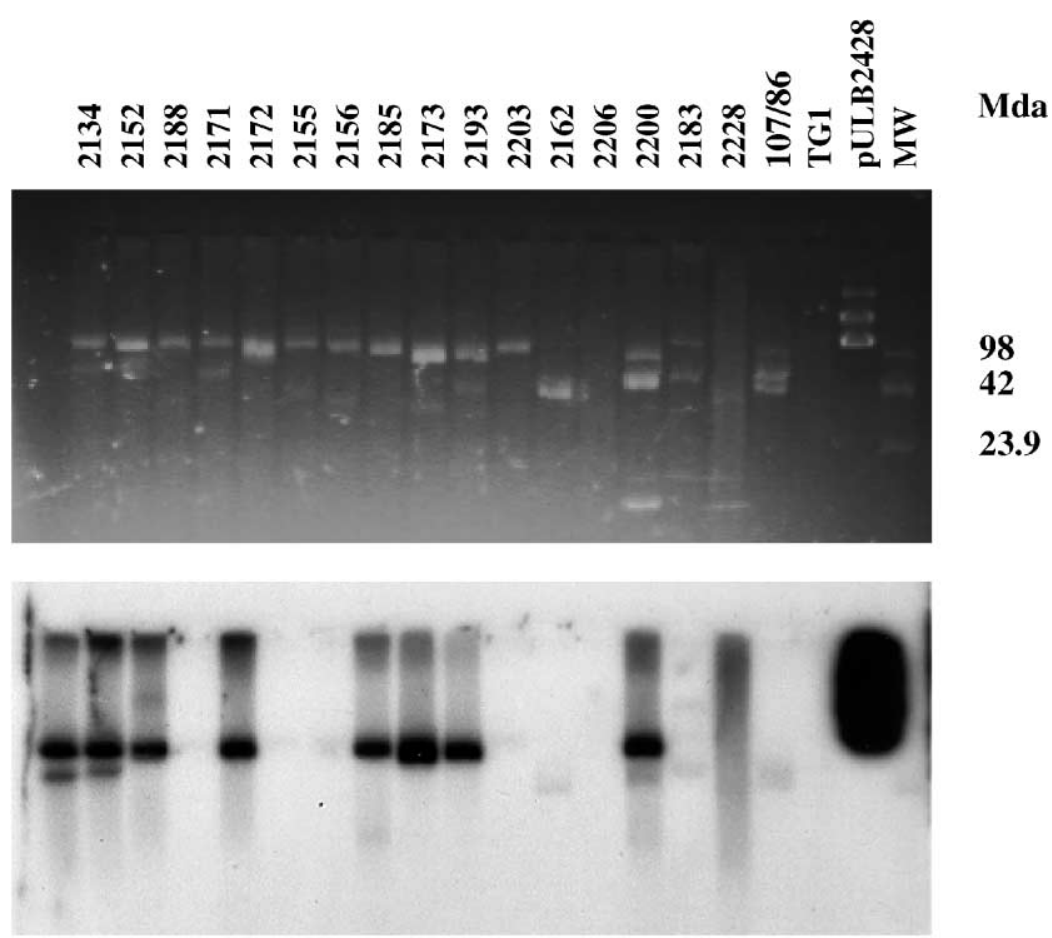

Fig. 4. Same plasmids as in Fig. 1 and their DNA hybridization analysis with replicon probe I1 (subtype of FIc) showing labelling of the plasmids of the tested ETEC and VTEC strains. Clear labelling for the positive control pULB2428 is seen (for I1).

plasmids studied were bireplicons (FIb and FIc) and some were of trireplicons (FIa, FIb and FIc).

F18 fimbrial genes were analysed originally from the total genome of the reference strain E. coli F107, because no horizontal transfer of the fimbrial operon was detectable (Imberechts et al., 1992). Indeed, only a few reports about the plasmid localization of the F18 genes are available (Dean-Nyström et al., 1993; Wittig et al., 1994; Mainil et al., 2002). No experiments had been performed to determine the replication origin of the plasmids bearing the F18ab or F18ac adhesin genes. Here, we have confirmed the plasmid localization of the F18ab and F18ac operons and determined the type of replication origin of their plasmids.

In our studies most of the strains harboured three high molecular weight plasmids (Table 2). In all the cases, only one of the large (higher than $23.9 \mathrm{MDa}$ ) plasmid bands hybridized with the radioactive F18-specific PCR product prepared from the 107/86 strain, confirming the plasmid localization of this virulence gene in both ETEC and VTEC strains. The size of the F18ab and F18ac plasmids seemed to be different between ETEC and VTEC strains. In ETEC strains, we found the F18ac gene on similar sized (about $98 \mathrm{MDa}$ ) plasmids, suggesting the horizontal spread of these adhesin plasmids between different ETEC isolates. In contrast, the size of the F18ab plasmids in the VTEC strains showed 
considerable variation (42-98 MDa), which could indicate that the F18ab operon could be randomly transmitted into the various indigenous plasmids of VTEC strains. These aspects should be further investigated. In any case, such replicon typing could be helpful in limited molecular epidemiologic surveys and in assessing the risks of recontamination of live oral nonpathogenic $E$. coli vaccine strains with virulence plasmids.

The ETEC virulence genes (for enterotoxins and adhesins) are often encoded in various combinations on the same high molecular weight plasmid (Mainil et al., 1992, 1998; Gyles, 1994; Smyth et al., 1994). In the present conjugation experiments, we found that the genes for adhesin (F18ac) and for haemolysin production are linked to the same large (98 MDa) self-transmissible plasmid.

\section{Acknowledgements}

Support of OTKA-A312 and of OTKA-T34970 projects from the Hungarian Basic Science Fund is acknowledged.

\section{References}

Alexa, P., Rychlik, I., Nejezchleb, A., Hamrik, J., 1997. Identification of enterotoxin producing strains of Escherichia coli by PCR and biological methods. Vet. Med. (Praha) 42, 97-100.

Bertschinger, H.U., Bachmann, M., Mettler, C., Pospischil, A., Schraner, E.M., Stamm, M., Sydler, T., Wild, P., 1990. Adhesive fimbriae produced in vivo by Escherichia coli O139:K12(B):H1 associated with enterotoxaemia in pigs. Vet. Microbiol. 25, 267-281.

Broes, A., Fairbrother, J.M., Mainil, J.G., Harel, J., Larivière, S., 1988. Phenotypic and genotypic characterization of enterotoxigenic Escherichia coli serotypes O8:K"2829” strains isolated from piglets with diarrhoea. J. Clin. Microbiol. 26, 2402-2409.

Carter, M.J., Milton, I.D., 1993. An inexpensive and simple method for DNA purifications on silica particles. Nucl. Acids Res. 25, 1044.

Couturier, M., Bex, F., Bergquist, P.L., Maas, W.K., 1988. Identification and classification of bacterial plasmids. Microbiol. Rev. 52, 375-395.

Dean-Nyström, E.A., Casey, T.A., Schneider, R.A., Moon, H.W., Nagy, B., 1993. A monoclonal antibody identifies 2134P fimbriae as adhesins on enterotoxigenic Escherichia coli isolated from postweaning piglets. Vet. Microbiol. 37, 101-114.

Gyles, C.L., 1994. Escherichia coli enterotoxins. In: Gyles, C.L. (Ed.), Escherichia coli in Domestic Animals and Humans. CAB International, Wallingford, UK, pp. 337-364.

Hess, J., Wels, W., Vogel, M., Goebel, W., 1986. Nucleotide sequence of a plasmid-encoded hemolysin determinant and its comparison with a corresponding chromosomal hemolysin sequence. FEMS Microbiol. Lett. 34, 1-11.

Imberechts, H., De Greve, H., Schlicker, C., Bouchet, H., Pohl, P., Charlier, G., Bertschinger, H., Wild, P., Vandekerckhove, J., Van Damme, J., Van Montagu, M., Lintermans, P., 1992. Characterization of F107 fimbriae of Escherichia coli 107/86, which causes edema disease in pigs, and nucleotide sequence of the F107 major fimbrial subunit gene, fedA strains that express adhesive fimbriae. Vet. Microbiol. 60, 19631971.

Imberechts, H., Van Pelt, N., De Greve, H., Lintermans, P., 1994. Sequences related to the major subunit gene fedA of F107 fimbriae in porcine Escherichia coli strains that express adhesive fimbriae. FEMS Microbiol. Lett. 119, 309-314.

Kado, C.I., Liu, S.T., 1981. Rapid procedure for detection and isolation of large and small plasmids. J. Bacteriol. $145,1365-1373$. 
Maas, R., Silva, R.M., Gomes, T.A., Trabulsi, L.R., Maas, W.K., 1985. Detection of genes for heat-stable enterotoxin I in Escherichia coli strains isolated in Brazil. Infect. Immun. 49, 46-51.

Mainil, J.G., Bex, F., Dreze, P., Kaeckenbeeck, A., Couturier, M., 1992. Replicon typing of virulence plasmids of enterotoxigenic Escherichia coli isolates from cattle. Infect. Immun. 60, 3376-3380.

Mainil, J.G., Daube, G., Jacquemin, E., Pohl, P., Kaeckenbeeck, A., 1998. Virulence plasmids of enterotoxigenic Escherichia coli isolates from piglets. Vet. Microbiol. 62, 291-301.

Mainil, J.G., Jacquemin, E., Pohl, P., Kaeckenbeeck, A., Benz, I., 2002. Plasmid co-localization of DNA sequences coding for the F18 fimbriae and AIDA adhesin in verocytotoxigenic Escherichia coli isolated from piglets. FEMS Microbiol. Lett., in press.

Maniatis, T., Fritsch, E.F., Sambrook, J., 1989. Molecular Cloning: A Laboratory Manual, 2nd Edition. Cold Spring Harbor Laboratory Press, Cold Spring Harbor, New York.

Nagy, B., Casey, T.A., Whipp, S.C., Moon, H.W., 1992. Susceptibility of porcine intestine to pilus-mediated adhesion by some isolates of piliated enterotoxigenic Escherichia coli increases with age. Infect. Immun. 60, 1285-1294.

Nagy, B., Whipp, S.C., Imberechts, H., Bertschinger, H.U., Dean-Nyström, E.A., Casey, T.A., Salajka, E., 1997. Biological relationship between F18ab and F18ac fimbriae of enterotoxigenic and verotoxigenic Escherichia coli from weaned pigs with oedema disease or diarrhoea. Microb. Pathog. 22, 1-11.

Rippinger, P., Bertschinger, H.U., Imberechts, H., Nagy, B., Sorg, I., Stamm, M., Wild, P., Wittig, W., 1995. Designations F18ab and F18ac for the related fimbrial types F107, 2134P and 8813 of Escherichia coli from porcine postweaning diarrhoea and from oedema disease. Vet. Microbiol. 45, 281-295.

Salajka, E., Salajkova, Z., Alexa, P., Hornich, M., 1992. Colonization factor different from K88, K99, F41 and 987P in enterotoxigenic Escherichia coli strains isolated from postweaning diarrhoea in pigs. Vet. Microbiol. 32, 163-175.

Smyth, C.J., Marron, M., Smith, S.G.J., 1994. Fimbriae of Escherichia coli. In: Gyles, C.L. (Ed.), Escherichia coli in Domestic Animals and Humans. CAB International, Wallingford, UK, pp. 399-436.

Wittig, W., Prager, R., Stamm, M., Strekel, W., Tshäpe, H., 1994. Expression and plasmid transfer of genes coding for the fimbrial antigen F107 in porcine Escherichia coli strains. Zentralbl. Bakteriol. 281, 130-139. 